\title{
Prevalence of leprosy cases in eastern Visayas, Philippines
}

\author{
Joseph. U.Almazan, $R N, M P M, M A N$ \\ College of Nursing and Health Sciences, Samar State University \\ *Corresponding author E-mail: almazanjoseph93@yahoo.com
}

\begin{abstract}
Leprosy is an important global health problem. Moreover, important for its potential to cause progressive and permanent physical disability. However, there is limited study conducted pertaining to the prevalence of leprosy in Eastern Visayas region, as well as to the association of its treatment, population, poverty rate, and gender. This study aimed to explore the prevalence of leprosy in terms of population growth, poverty rate, its treatment, and to determine association between provinces and the type of leprosy treatment for both completed and continuing treatment, between newly diagnosed (2010) and population in its provinces, between average per capita (2001-2009) and continuing treatment of leprosy (2001-2009) between the completed treatment (2001-2009) and population (2001-2009), leprosy cases (2010) between sexes among provinces. It employed descriptive inferential design, and utilizing chi-square test with the used of SPSS version 19. Findings revealed that there were no significant association between provinces and the type of leprosy treatment for both completed and continuing treatment, between newly diagnosed (2010) and provinces, between average per capita (2001-2009) and continuing treatment of leprosy(2001-2009)between the completed treatment (2001-2009) and population (2001-2009), leprosy cases (2010) between sexes among provinces. Finding of this investigation suggests everyone is prone to leprosy, whether or not it's male or female, and rich or poor. Furthermore, studies identifying other factors like literacy rate, present health status could also be investigated.
\end{abstract}

Keywords: Prevalence, Leprosy, Poverty rate.

\section{Introduction}

Leprosy is an important global health problem. There were estimated of 4 million persons to have the debilitating disease. It is also mentioned About 600, 000 new cases were being detected annually and about 2400 million people live in countries with a leprosy prevalence of $>1$ per 10000 [1].In addition, of all the contagious diseases, leprosy is highly important for its potential to cause permanent and progressive physical disability [2]. The disease, particularly the visible disability, contributes to intense social stigma and social discrimination of patients.

Leprosy is caused by Mycobacterium leprae with incubation period from 5 to 15 years [3]. Lepromatous patients shed mycobacteria in their nasal secretions thereby continuing infection and highly communicable. It is also shown, the disease is more common in tropical countries, and the largest numbers of leprosy patients continue to be in Southeast Asia and Central Africa.

In Southeast Asia particularly in the Philippines, there were 38,570 leprosy patients in the country with a prevalence rate of 7.2 per 10,000 Filipinos [4]. In 2010, DOH acclaimed 1 per 2,000 new leprosy cases. Ilocos area has the highest number of leprosy cases, followed by Bohol and (Sultan Kudarat, Sarangani, Cotabato, South Cotabato, and General Santos) [4].

Meanwhile, in Eastern Visayas, there were still several leprosy cases were reported despite the National Leprosy Control Program (NLCP) made by the DOH to eradicate the disease [5].These data had important and very different public health consequences. There still imperfect understanding of the transmission and of leprosy and the importance of various factors in disease causation still influences the general health. [6]

Moreover, several studies link between poverty and leprosy, but were difficult to demonstrate at community, national, and even individual levels. A study done in Malawi showed that living in a crowded household was a risk factor. This study shows at a community level in a high endemic area of leprosy in Brazil the population growth, level of inequality, and presence of a railroad was associated with higher levels of leprosy. Furthermore, Populations with high poverty rate have the poorest health status [7].

However, despite many researchers conducted on the prevalence of leprosy in the country, there is limited study conducted pertaining to the prevalence of leprosy in Eastern Visayas region, as well the association of its treatment, 
population, poverty rate, and gender [8]. While leprosy is no longer a public health threat in the country, more than 1,000 Filipinos still get infected with the disease every year [26].Finally, leprosy has not only a physical effect, but also a social and economic impact. Thus, it is inspiration of a researcher to conduct this investigation.

\section{Research objectives}

This study aimed to explore the prevalence of leprosy in terms of population growth, average per capita,the association between the type leprosy treatment leprosy (newly diagnosed, continuing treatment, completed treatment) cases per province, and association of leprosy cases (2010) between the sexes among provinces.

\section{Materials and Method}

\subsection{Design}

This study aimed to determine the prevalence of leprosy in Eastern Visayas, employed descriptive inferential design. This design is appropriate for the study focused on secondary data of DOH, and hypothesis testing with the used of SPSS version 19.The researcher utilized descriptive statistics such as percentages, mean, frequency counts. Moreover, comparative analysis utilizing chi-square test for related samples with 0.05 level of significance was used to measure the associationof:1) The Provinces and the Type of Leprosy Treatment for both Completed and Continuing treatment, 2)Newly diagnosed (Leprosy, 2010) and Provinces3)Average per capita (2001-2009) and Continuing Treatment of Leprosy(2001-2009)4)completed treatment (2001-2009) and population (2001-2009)5)Leprosy Cases (2010) Between Sexes among Provinces

\subsection{Participants}

The respondents of this study were the total population per provinces from 2001-2010, and leprosy patients since 20012010 in Eastern Visayas (Region 8)

\subsection{Ethical Consideration}

The researcher sends a permission letter from the Department of Heath Eastern Visayas Regional Office, for the data on leprosy cases from 2001-2010.This include continuing treatment, completed treatment and new leprosy cases (2010). The permission letter was approved by the Ethics Committee of Department of Heath Eastern Visayas Regional Office. Confidentiality of information of respondents was observed based in accordance on the approved protocol by the department. Likewise, the researchers send a permission letter for the population data from 2001-2010 in the National Statistics Office and National Coordination Board for the poverty rate. After which the email of approval came out.

\subsection{Instrumentation}

The researcher utilized the population data statistics data of Eastern Visayas (2001-2010) National statistics office, leprosy cases from DOH which contains continuing treatment (2001-2010) and new cases in 2010. Relatively reliable registration and patient records were available. Moreover, the poverty rate was retrieved from the National Statistical coordination board.

\subsection{Data analysis}

The researchers utilized both descriptive as well as inferential statistical tools, such as frequency count which used to present province's population in Eastern Visayas (Region 8) from 2001-2010, poverty prevalence, and leprosy cases(2001-2010).Moreover, Chi- Square to measure the association of 1) newly diagnosed with leprosy(2010) and Population (2010), 2) average per capita (2001-2009) and Population (2001-2009), 3) completed treatment(2001-2009) and population(2001-2009), 4) and sexes among provinces. 


\section{Main results}

The data presented in table 1 was the Population in Region VIII by Provinces from 2001-2010. Northern Leyte has the highest total population of $13,852,541$ individual while Biliran, Leyte has the lowest population of $1,565,631$ individuals. Each province differs on their population throughout the entire region

Table 1: Population in Eastern Visayas (Region 8) by Provinces from 2001-2010

\begin{tabular}{|c|c|c|c|c|c|c|}
\hline Year & Northern Leyte & Southern Leyte & Biliran & Eastern Samar & Northern Samar & Western Samar \\
\hline 2001 & $1,351,903$ & 361,041 & 150,793 & 403,701 & 510,595 & 517,334 \\
\hline 2002 & $1,377,661$ & 368,552 & 154,022 & 410,544 & 519,455 & 527,375 \\
\hline 2003 & $1,301,510$ & 314,432 & 146,048 & 386,089 & 533,898 & 517,541 \\
\hline 2004 & $1,316,255$ & 323,453 & 148,083 & 389,799 & 545,631 & 525,763 \\
\hline 2005 & $1,331,367$ & 332,754 & 150,172 & 393,631 & 557,704 & 534,168 \\
\hline 2006 & $1,347,241$ & 342,350 & 152,321 & 397,451 & 570,125 & 542,688 \\
\hline 2007 & $1,449,745$ & 329,150 & 164,400 & 434,200 & 591,300 & 580,822 \\
\hline 2008 & $1,337,616$ & 314,308 & 151,992 & 409,784 & 557,038 & 537,613 \\
\hline 2009 & $1,505,425$ & 341,025 & 172,000 & 452,200 & 618,100 & 607,248 \\
\hline 2010 & $1,533,818$ & 347,525 & 175,800 & 461,300 & 631,900 & 621,038 \\
\hline Grand Total & $13,852,541$ & $3,374,590$ & $1,565,631$ & $4,138,699$ & $5,635,746$ & $5,511,590$ \\
\hline
\end{tabular}

Table 2 showed the poverty prevalence of the entire Eastern Visayas. Looking at the table, each province is being differed on the Annual Per Capita Poverty Threshold, Poverty Incidence among Families and the Magnitude of poverty. At the Annual Per Capita Poverty Threshold of the years 2003, 2006 and 2009 in table 2 Biliran was found to be the lowest and Southern Leyte was the highest. On the case of Poverty Incidence among Families in Estimates, Western Samar got the lowest in 2003, Southern Leyte in 2006 and Northern Samar in 2009 while the highest on the Poverty Incidence Estimates in the years mentioned was Northern Samar. On the coefficient of variation under poverty incidence among Families, Biliran was the lowest in 2003 and Northern Leyte in 2006 and 2009. The highest in the coefficient of variation in 2003 was Eastern, Samar and Biliran, Leyte in 2006 and 2009. Furthermore, on the case of Magnitude of Poverty Estimates, Biliran was the lowest in 2003, 2006 and 2009 while Northern Leyte was the highest in the mentioned years respectively.

Table 2: Poverty rate

\begin{tabular}{|c|c|c|c|c|c|c|c|c|c|c|c|c|}
\hline \multirow[t]{2}{*}{ Region VII } & \multirow{2}{*}{\multicolumn{3}{|c|}{$\begin{array}{l}\text { Annual Per Capita Poverty } \\
\text { Threshold (in Pesos) }\end{array}$}} & \multicolumn{6}{|c|}{ Poverty Incidence Among Families (\%) } & \multirow{2}{*}{\multicolumn{3}{|c|}{$\frac{\text { Magnitude of poverty }}{\text { Estimates }}$}} \\
\hline & & & & \multicolumn{3}{|c|}{ Estimates $(\%)$} & \multicolumn{3}{|c|}{ Coefficient of Variation } & & & \\
\hline & 2003 & 2006 & 2009 & 2003 & 2006 & 2009 & 2003 & 2006 & 2009 & 2003 & 2006 & 2009 \\
\hline Biliran & 9,225 & 11,071 & 15,022 & 32.3 & 25.6 & 28.0 & 7.3 & 33.0 & 23.1 & 9,508 & 8,216 & 11,616 \\
\hline Eastern Samar & 10,106 & 12,195 & 16,385 & 29.8 & 37.6 & 45.8 & 19.0 & 9.5 & 10.9 & 22,642 & 31,165 & 41,359 \\
\hline Northern Leyte & 9,613 & 11,570 & 15,500 & 29.2 & 28.5 & 27.8 & 8.9 & 9.0 & 8.8 & 99,082 & 104,260 & 110,214 \\
\hline Northern Samar & 10,374 & 12,509 & 16,684 & 37.4 & 43.3 & 41.7 & 15.5 & 14.7 & 13.5 & 38,393 & 47,234 & 45,023 \\
\hline Southern Leyte & 10,383 & 12,516 & 16,707 & 28.7 & 22.6 & 30.3 & 14.6 & 9.5 & 14.3 & 21,605 & 18,403 & 24,389 \\
\hline Western Samar & 9,628 & 11,594 & 15,512 & 27.5 & 30.8 & 36.9 & 15.5 & 13.1 & 12.3 & 36,229 & 44,068 & 54,554 \\
\hline
\end{tabular}

Table 3 showed the Leprosy cases which were grouped as newly diagnosed, continuing treatment, completed treatment cases in Eastern Visayas, data per year and area. In the Newly Diagnosed in 2010, Southern Leyte was the lowest and Northern Samar was the highest. On the other hand, Southern Leyte has lowest number of patients in the Continuing Treatment and Biliran has the highest number of patients. In the Completed Treatment Biliran, Leyte has the lowest number of Patients completed the treatment for leprosy and Northern Leyte was the highest.

\begin{tabular}{|c|c|c|c|c|c|c|c|c|}
\hline Province & $\begin{array}{c}\text { Newly } \\
\text { diagnosed } \\
(2010)\end{array}$ & Percentage & $\begin{array}{c}\text { Continuing } \\
\text { treatment }\end{array}$ & Percentage & $\begin{array}{c}\text { Completed } \\
\text { treatment }\end{array}$ & Percentage & $\begin{array}{c}\text { Total } \\
\text { Cases }\end{array}$ & Percentage \\
\hline Biliran & 147 & 9.46 & 732 & 29.28 & 84 & 5.86 & 963 & 17.55 \\
\hline Eastern Samar & 213 & 13.71 & 195 & 7.8 & 154 & 10.75 & 562 & 10.24 \\
\hline Northern Leyte & 102 & 6.56 & 611 & 24.44 & 598 & 41.73 & 1311 & 23.89 \\
\hline Northern Samar & 708 & 45.56 & 323 & 12.92 & 237 & 16.54 & 1268 & 23.11 \\
\hline Southern Leyte & 98 & 6.31 & 121 & 4.84 & 97 & 6.77 & 316 & 5.76 \\
\hline Western Samar & 286 & 18.40 & 518 & 20.72 & 263 & 18.35 & 1067 & 19.45 \\
\hline Grand Total & 1554 & 100 & 2500 & 100 & 1433 & 100 & 5487 & 100 \\
\hline
\end{tabular}

Table4 showed the average Poverty incidence of the provinces of Region VIII. Based on the Average Per Capita Poverty Threshold in Pesos, Biliran has the lowest while Southern Leyte was the highest. With regards to the Poverty Incidence among families in the Estimates, Southern Leyte has the lowest estimates while Northern Samar was the highest. In the Coefficient of Variation, Leyte was the lowest while Biliran was the highest. On the other hand, with regards to the Magnitude of Poverty, Biliran, Leyte has the lowest magnitude estimate while Leyte was the highest. 
Table 4: Average poverty Rate (2003-2009)

\begin{tabular}{|c|c|c|c|c|}
\hline \multirow[t]{2}{*}{ Region VII } & \multicolumn{2}{|c|}{$\begin{array}{c}\text { Average Per Capita Poverty } \\
\text { Threshold } \\
\text { (in Pesos) 2003-2009 }\end{array}$} & $\begin{array}{l}\text { Poverty Rate Among Families (\%) } \\
\text { 2003-2009 }\end{array}$ & \multirow{2}{*}{$\begin{array}{c}\text { Magnitude of } \\
\text { poverty } \\
2003-2009 \\
\text { Estimates }\end{array}$} \\
\hline & & Estimates (\%) & Coefficient of Variation & \\
\hline Biliran & 11,773 & 28.6 & 21.13333 & 9,780 \\
\hline Eastern Samar & $12,895.30$ & 37.7 & 13.13333 & 31,722 \\
\hline Leyte & $12,227.7$ & 28.5 & 8.9 & $104,518.70$ \\
\hline Northern Samar & 13,189 & 40.8 & 14.56667 & 43,550 \\
\hline Southern Leyte & 13,202 & 27.2 & 12.8 & 21,466 \\
\hline Western Samar & $12,244.7$ & 31.7 & 13.63333 & 44,950 \\
\hline
\end{tabular}

Table 5 showed the association between the provinces and the type of leprosy treatment for both completed and continuing treatment. Out of 2500 individuals continuing the treatment against leprosy, Biliran had the highest with 731 patients and Southern Leyte was the lowest with 121 patients. On the other hand, 1,433 patients completed the treatment and with this number, Northern Leyte got the highest with 508 patients completed the treatment while Biliran was the lowest with 84 patients.

Table 5: Association between provinces and the type of leprosy treatment for both completed and continuing treatment

\begin{tabular}{|c|c|c|c|}
\hline \multirow[t]{2}{*}{ Province } & \multicolumn{2}{|c|}{ Type of leprosy treatment } & \multirow[t]{2}{*}{ Chi- Square test Asymp Sig. (2-sided) } \\
\hline & Continuing treatment & Completed treatment & \\
\hline Biliran & 732 & 84 & \\
\hline Eastern Samar & 195 & 154 & \\
\hline Northern Leyte & 611 & 598 & .220 \\
\hline Northern Samar & 323 & 237 & \\
\hline Southern Leyte & 121 & 97 & \\
\hline Western Samar & 518 & 263 & \\
\hline Total & 2500 & 1433 & \\
\hline
\end{tabular}

Table 6 provides information on the association between newly diagnosed (Leprosy, 2010), total population of the province indicated and the name of the province itself. It is indicated in the table the dependency between newly diagnosed (Leprosy, 2010) and Population (2010). It showed that Southern Leyte had the lowest newly diagnosed patients with Leprosy as of 2010 with a population of 347,525 while Northern Samar was the highest newly diagnose patients with leprosy with a population of 631,900.Meanwhle, the Chi- Square test has Asymp. Sig. (2-sided) of .224 in its province.

Table 6: Association between newly diagnosed (leprosy, 2010) and provinces

\begin{tabular}{|c|c|c|c|}
\hline Provinces & Newly diagnosed (Leprosy,2010) & Population & Chi- Square test Asymp. Sig. (2-sided) \\
\hline Biliran,Leyte & 147 & 175,800 & \multirow{6}{*}{.224} \\
\hline Eastern Samar & 213 & 461,300 & \\
\hline Leyte & 102 & $1,533,818$ & \\
\hline Northern Samar & 708 & 631,900 & \\
\hline Southern Leyte & 98 & 347,525 & \\
\hline Western Samar & 286 & 621,038 & \\
\hline
\end{tabular}

Table 7 presents the association between average per capita (2001-2009) and continuing treatment of leprosy (20012009). Eastern Samar has the highest average per capita (2001-2009), while Biliran, Leyte has the lowest average per capita among the provinces in Region 8.Meanwhile, in terms of continuing treatment of leprosy (2001-2009),Biliran,, Leyte has the highest number of leprosy cases accounting to 732 cases, while Southern, Leyte has lowest number undergoing treatment of leprosy respectively.

Table 7: Association between average per capita (2001-2009) and continuing treatment of leprosy (2001-2009)

\begin{tabular}{|c|c|c|c|}
\hline Provinces & Average per capita (2001-2009) & $\begin{array}{l}\text { Continuing treatment of leprosy(2001- } \\
2009)\end{array}$ & $\begin{array}{c}\text { Chi- Square test } \\
\text { Asymp.Sig. (2-sided) }\end{array}$ \\
\hline Biliran,Leyte & 11773 & 732 & \multirow{6}{*}{.224} \\
\hline Eastern Samar & 12895.30 & 195 & \\
\hline Northern Leyte & 12227.70 & 611 & \\
\hline Northern Samar & 13189 & 323 & \\
\hline Southern Leyte & 13202 & 121 & \\
\hline Western Samar & 12244.70 & 518 & \\
\hline
\end{tabular}

Table 8 illustrates associations between completed treatment of leprosy (2001-2009) and population (2001-2009). In terms of completed treatment in each province and its population. Biliran, Leyte was the lowest accounting to 84 cases 
with 175, 800popuation while Northern, Leyte has the highest which has 598 cases and a population of 1,533,818, it has a Chi- Square test of Asymp. Sig. (2-sided) .285.

Table 8: Associations between the completed treatment (2001-2009) and population (2001-2009)

\begin{tabular}{ccc} 
& Table 8: Associations between the completed treatment (2001-2009) and population (2001-2009) & $\begin{array}{c}\text { Chi- Square test Asymp. } \\
\text { Sig. (2-sided) }\end{array}$ \\
\hline Provinces & Completed treatment & Population 2001-2009 \\
Biliran,Leyte & 84 & 175800 \\
Eastern Samar & 154 & 461300 \\
Northern Leyte & 598 & $1,533,818$ \\
Northern Samar & 237 & 631900 \\
Southern Leyte & 97 & 347525 \\
Western Samar & 263 & 621,038 \\
\hline
\end{tabular}

Table 9 presents association of leprosy cases (2010) between sexes among provinces. Among the provinces, Northern Leyte has the highest male population of 986,500 with 43 leprosy cases while Biliran, Leyte has the lowest male population of 89,100with 3 leprosy cases. Furthermore, its chi- Square test Asymp. Sig. (2-sided) has .242 result. Meanwhile, as to female population (2010), Northern Leyte has the highest male population of 952,800 with 43 leprosy cases while Biliran,Leyte has the lowest male population of 86,700with 3 leprosy cases, it has chi- Square test Asymp. Sig. (2-sided) has .242 result.

Table 9: Association of leprosy cases (2010) between sexes among provinces

\begin{tabular}{cccccc}
\hline Provinces & $\begin{array}{c}\text { Male Population } \\
(2010)\end{array}$ & $\begin{array}{c}\text { Leprosy } \\
\text { cases } \\
(2010)\end{array}$ & $\begin{array}{c}\text { Chi- Square test } \\
\text { Asymp. } \\
\text { Sig. (2-sided) }\end{array}$ & $\begin{array}{c}\text { Female } \\
\text { Population } \\
(2010)\end{array}$ & $\begin{array}{c}\text { Leprosy } \\
\text { cases } \\
(2010)\end{array}$ \\
\hline Biliran, Leyte & 89,100 & 3 & .242 & 86,700 & 3 \\
Eastern Samar & 235,200 & 16 & & 226,100 & 16 \\
Sig. (2-sided) & 952,800 & 43 \\
Northern Leyte & 986,500 & 43 & 310,600 & 14 \\
Northern Samar & 321,300 & 14 & 212,800 & 3 \\
Southern Leyte & 220,300 & 3 & 393,600 & 32 \\
Western Samar & 412,500 & 32 & & \\
\hline
\end{tabular}

\section{Discussions}

This study explored the prevalence of leprosy in Eastern Visayas region, population growth 2001-2010, and poverty rate. Moreover the investigation analyzed any significant association between the type leprosy treatment leprosy (newly diagnosed, continuing treatment, completed treatment) cases per province, and association of leprosy cases (2010) between the sexes among provinces.

Findings revealed that there was no association between provinces and the type of leprosy treatment for both completed and continuing treatment. This is worth noting since the previous study pointed out that despite the great progress in eliminating leprosy using Multi- Drug treatment (MDT) in the world, patients with leprosy are not evenly distributed in countries where the disease is endemic, thus there was still leprosy cases and cannot be eliminated abruptly [9][10].

Moreover, there was no association between newly diagnosed (2010) and population in each province. It also affirms to the previous study that clinically, leprosy can simulate many kinds of skin diseases and neuropathic problems, making early diagnosis and treatment difficult in a distant area[11].However, Studies have shown that geographical area, the type of leprosy in treatment, and genetic relationship were the determinants for the development of leprosy.[12]To complete treatment is usually an independent choice of patients[13] But for a successful treatment outcome, there needs to be input from both health service provider and client seeking care.

Moreover the newly diagnosed leprosy cases in 2010 in each province have no significant association of its population in 2010.Indeed, this negates that leprosy was related to uncontrolled urbanization and rapid increase in population and poverty [14]. Study shown at a community level in a high endemic were of leprosy in Brazil population growth, the level of inequality, were associated with higher levels of leprosy. [15][16]

Moreover there was no association between the completed treatment (2001-2009) and population (2001-2009). This affirms to the previous study that to complete treatment is usually an independent choice of patients. In link with this, there needs to be input from both health service provider and client seeking care [17].Furthermore, it means that average per capita in its province was not related to patients who were undergoing treatment of leprosy. This findings refutes to the previous study that leprosy is associated with a high level of poverty and uncontrolled urbanization which emphasized that was slow in annual household capita [18].Likewise, The Kerr-Pontes study shows at a community level in a high endemic area of leprosy in Brazil the level of disparity, increased population, and the presence of a railroad are associated with higher levels of leprosy. Population growth and inequality may cause over-crowding so facilitating 
transmission of M. leprae [19][20].Finally, Central findings revealed that there was no significant association of leprosy cases (2010) between the sexes among its provinces. This negates to previous studies that male were risk of contracting disease compared to female contacts [21]

\section{Conclusion}

Finding of this investigation suggest everyone is at risk in developing leprosy, whether it is male or female, and rich or poor, therefore, no one is exempted. These results support the previous studies[22][23][24][25][26].However, the data need to be interpreted with caution considering it is a secondary data and does not know exactly how the data collection process was done and how well it was done. Future studies needed to further reduce the disease burden and to sustain ascertain activities, inclusive the detection of remaining hidden and new cases in all vulnerable populations. Furthermore, studies identifying other factors like literacy rate, present health status may be investigated.

\section{Acknowledgements}

This research study would was impossible without the help of several people who humbly and kindly contributed and made time to assist in preparing for the completion of this study, especially to Dr. Flora belle Patosa. Moreover, sincerest thanks and profound gratitude to all those who made this study possible.

\section{Competing Interest}

The authors have no competing interests which may have influenced in writing this article.

\section{References}

[1] Noordeen S.K. 1995. Elimination of leprosy as a public health problem: progress and prospects.;73(1):1-6.PMID:7704919

[2] Naveen Frank2006 Sumanahalli - Village of people of Good Hearts http://www.daijiworld.com/chan/exclusive_arch.asp?ex_id=241

[3] Leprosy Statistics WHO.1994http://diseases.emedtv.com/leprosy/leprosy-statistics.html

[4] Pots de Leon, 2012.Philippines still has pockets of leprosy cases.http://www.interaksyon.com/article/22842/philippines-still-has-pockets-ofleprosy-cases

[5] GaspayGayB2013Gov'tactstoeradicateleprosywhichstillhauntsRegionhttp://archives.pia.gov.ph/?m=12\&sec=reader\&rp=3\&fi=p060306.htm\& no $=21 \&$ date $=03 / 06 / 2006$

[6] Diana NJ LockwoodCommentary: Leprosy and poverty Oxford JournalsMedicineInternational Journal of EpidemiologyVolume 33, Issue 2Pp. 269-270 http://ije.oxfordjournals.org/content/33/2/269.full

[7] Diana NJ Lockwood. Commentary: Leprosy and poverty Oxford Journals Medicine International Journal of Epidemiology Volume 33, Issue 2Pp. 269-270http://ije.oxfordjournals.org/content/33/2/269.full

[8] Srinivasan H.1995. Deformity and disability-unfinished agenda in leprosy work. LeprRev, 66:193-200.

[9] Leprosy global situation. World Health Organization. Weekly Epidemiol Rec, 2000; 75: 226-231.,

[10] Current epidemiology of leprosy in India. Lepr Rev, 2006; 77(4):292-294.

[11] Pfaltzgraff RE, Ramu P. 1994.Clinical leprosy: in: Hastings RC, Leprosy 2nd, Churchill Livingstone,

[12] Moet FJ, Meima A, Oskam L, Richardus J. 2004.Risk factors for the development of clinical leprosy among contacts, and their relevance for targeted interventions. Lepr Rev, 2004; 75:310-326.

[13] Garner P, Volmink J. 1997.Systematic review of randomized controlled trials of strategies to promote adherence to tuberculosis treatment. BMJ, 315: 1403 \pm 1406 .

[14] Pontes ,Ligia Regina Sansigolo Kerr-, Montenegro ,Ana Cláudia Dorta , Barreto Maurício Lima , Werneck Guilherme Loureiro and Hermann ,Feldmeier. 2003.Inequality and leprosy in Northeast Brazil: an ecological study

[15] Lockwood. Diana NJ2004. Commentary: Leprosy and poverty. IJE vol.33 no.2 International Epidemiological Association 2004; all rights reserved. International Journal of Epidemiology 2004;33:269-270 DOI: 10.1093/ije/dyh115

[16] Ligia RS Kerr-Pontes, Barreto, Maurı'cio L, Evangelista, Clara MN, Rodrigues,Laura, Heukelbach C Jorg, Feldmeier, Hermann Socioeconomic, environmental, and behavioral risk factors for leprosy in North-east Brazil: results of a case-control study. Published by Oxford University Press on behalf of the International Epidemiological Association International Journal of Epidemiology 2006; 35:994-1000 doi:10.1093/ije/dyl072

[17] Griffiths, Stephen and Ready, Natasha 2001. Defaulting patterns in a provincial leprosy control programme in Northern Mozambique MocËambique. Lepr Rev (2001) 72, 199 205.

[18] Pontes ,Ligia ,Regina Sansigolo Kerr-1, Montenegro ,Ana Cláudia Dorta 1, Barreto Maurício Lima 2, Werneck Guilherme Loureiro 3 and Feldmeier Hermann 2003.Inequality and leprosy in Northeast Brazil: an ecological study

[19] Diana NJ Lockwood. 2004. Commentary: Leprosy and poverty. IJE vol.33 no.2. International Journal of Epidemiology 2004;33:269-270 DOI: 10.1093/ije/dyh115

[20] Ligia RS Kerr-Pontes, Barreto Maurı'cio L, Evangelista Clara MN,Rodrigues, Laura C, Heukelbach Jorg, and Hermann Feldmeier 2006. Socioeconomic, environmental, and behavioral risk factors for leprosy in North-east Brazil: results of a case-control study. Published by 
Oxford University Press on behalf of the International Epidemiological Association International Journal of Epidemiology 2006;35:994-1000 doi:10.1093/ije/dyl072

[21] Fine P. E. M., Steme J. A. C., Pönnighaus J. M., Bliss L., Saul J., Chihana A., MunthaliM. and Wamdorff D.K. 1999. Household and Dwelling Contact as Risk Factors for Leprosy in Northern Malawi. Oxford Journals Medicine American Journal of Epidemiology Volume 146, Issue 1 Pp. 91-102

[22] Global Strategy for Further Reducing the LeprosyBurden and Sustaining Leprosy Control Activities (Operational Guideline2006-2010).2006. World Health Organization, Regional Office for South-East Asia, New Delhi.

[23] Moet FJ, Meima A, Oskam L, Richardus JH. Risk factors for the development of clinical leprosy among contacts, and their relevance for targeted interventions. Lepr Rev, 2004; 75:310-326.

[24] Sterne JAC, Ponnighaus JM, et al. Household and dwelling contact as risk factors for leprosy in northern Malawi. Am J Epidemiol, 1997; 146:91-102? Van Beers SM, Hatta M and Klatser PR. Patient contact is the major determinant in incident leprosy: implications for future control. Inter J Lepr, 1999; 67(2):119-128.

[25] Bakker MI, May L, Hatta M et al. Genetic, household and spatial clustering of leprosy on an island in Indonesia: a population-based study. BMC Med Genetics, 2005; 6:40-50.

[26] Moet FJ, Pahan D, Schuring RP et al. Physical distance, genetic relationship, age, and leprosy classification are independent risk factors in contacts of patients with leprosy. JID, 2006; 193:346-35328-32' 